\title{
Relationship between social and cognitive functions in people with schizophrenia
}

This article was published in the following Dove Press journal:

Neuropsychiatric Disease and Treatment

Takeo Tominaga,' Masahito

Tomotake, ${ }^{2}$ Tomoya

Takeda,' Yoshinori Ueoka, ${ }^{3}$

Tsunehiko Tanaka, ${ }^{4}$

Shin-ya Watanabe,' Naomi

Kameoka, ${ }^{5}$ Masahito

Nakataki, ${ }^{5}$ Shusuke

Numata, ' Yumiko Izaki, ${ }^{6}$

Satsuki Sumitani, ${ }^{7}$ Hiroko

Kubo, ${ }^{8}$ Yasuhiro Kaneda, ${ }^{9}$

Tetsuro Ohmori'

'Department of Psychiatry, Graduate

School of Biomedical Sciences,

Tokushima University, Tokushima,

Japan; ${ }^{2}$ Department of Mental Health,

Graduate School of Biomedical

Sciences, Tokushima University,

Tokushima, Japan; ${ }^{3}$ Field of Psychology,

Department of Human Sciences,

Graduate School of Technology,

Industrial and Social Sciences,

Tokushima University, Tokushima, Japan;

${ }^{4}$ Faculty of Education, Specialized

Courses Educational Psychology,

Niigata University, Niigata, Japan;

${ }^{5}$ Department of Psychiatry, Tokushima

University Hospital, Tokushima, Japan;

${ }^{6} \mathrm{Health}$ Service and Counseling

Center, Tokushima University,

Tokushima, Japan; ${ }^{7}$ Academic Support

Office for Students with Special Needs,

Tokushima University, Tokushima, Japan;

${ }^{8}$ Department of Psychiatry, Aizato

Hospital, Itano-gun, Tokushima, Japan;

'Department of Psychiatry, Iwaki

Clinic, Anan, Tokushima, Japan

Correspondence: Takeo Tominaga

Department of Psychiatry, Graduate

School of Biomedical Sciences, Tokushima

University, 3-18-15, Kuramoto-cho,

Tokushima 770-8503, Japan

$\mathrm{Tel}+81886337130$

Fax +8I 886337131

Email kaisei_tomy0076@yahoo.co.jp
Purpose: The purpose of the present study was to examine clinical factors related to social function in people with schizophrenia.

Patients and methods: The participants were 55 stabilized outpatients with schizophrenia. Their mean age was 39.36 ( $\mathrm{SD}=10.65$ ) years. Social function was assessed using the Quality of Life Scale (QLS). Cognitive function was evaluated with the Measurement and Treatment Research to Improve Cognition in Schizophrenia Consensus Cognitive Battery (MCCB). Clinical symptoms were assessed using the Positive and Negative Syndrome Scale (PANSS), the Calgary Depression Scale for Schizophrenia, and the Drug-Induced Extrapyramidal Symptoms Scale. Results: Neither the MCCB cognitive domain score nor composite score was correlated with the QLS scores. However, of the 10 MCCB subtests, the Trail Making Test Part A and the Brief Assessment of Cognition in Schizophrenia-Symbol Coding (BACS-SC) scores were positively correlated with the QLS scores. Among clinical variables, especially the PANSS negative syndrome scale score had a strong negative correlation with the QLS scores. Stepwise regression analyses showed that the PANSS negative syndrome scale score was an independent predictor of the QLS scores, and although the BACS-SC score predicted the QLS common objects and activities subscale score, the association was not so strong compared to the PANSS negative syndrome scale score.

Conclusion: These results indicate that speed of processing evaluated by BACS-SC could predict some aspect of social function but negative symptoms have a much stronger impact on global social function in people with schizophrenia.

Keywords: schizophrenia, social function, negative symptom, cognitive function, speed of processing

\section{Introduction}

Although there is heterogeneity with respect to the functional outcome of schizophrenia patients, ${ }^{1}$ poor functional outcome is often observed. ${ }^{2-6}$ Functional outcome is defined as a wide range of real-world functions including independent living, financial management, employment, and leisure/social activities. ${ }^{7,8}$ So, social function investigated in this study is considered to be a part of functional outcome. ${ }^{9}$ Finding contributors to functional outcome is an important issue in schizophrenia research and clinical intervention. Previous studies have shown that several clinical factors such as positive ${ }^{10-15}$ and negative symptoms, ${ }^{10-20}$ depressive symptoms, ${ }^{11,12,15,16,21,22}$ and extrapyramidal symptoms ${ }^{11,15,17,19,20}$ are associated with functional impairments.

Recently, much more attention has been paid to cognitive impairment as it is a core feature of schizophrenia. ${ }^{23,24}$ Cognitive impairment persists through the illness including premorbid period, ${ }^{25,26}$ and patients with schizophrenia show about 1-1.5 SD deficits compared to healthy controls in several cognitive domains, particularly memory, 
attention, executive function, and speed of processing. ${ }^{27-29}$ In schizophrenia research, cognitive function is broadly divided into neurocognition and social cognition. ${ }^{30}$ Previous studies have indicated that neurocognition such as verbal memory, working memory, executive function, and vigilance are related to functional outcome in people with schizophrenia. ${ }^{31-33}$ And, it is notable that neurocognition may explain $20 \%-60 \%$ of the variance of functional outcome and it may be a stronger predictor than symptomatology. ${ }^{33-35}$ On the other hand, some previous studies have suggested that symptomatology is more influential in functional outcome than neurocognition. ${ }^{15,36-38}$ Among the previous studies, Ertuğrul and Uluğ and Norman et al found no relationship between neurocognition and functional outcome. ${ }^{36,38}$ More recently, social cognition, referred to as an array of abilities that involve cognitive capability applied to social situations, ${ }^{30}$ has attracted attention as it is also related to functional outcome. ${ }^{39}$ The inconsistency among previous studies can be explained by difference of study design, sample population, sample size, cognitive tests, and functional outcome scales; especially, as for assessing cognitive function and functional outcome in people with schizophrenia, researchers have used different neuropsychological tests and functional outcome scales. Therefore, comparisons across studies seem to be difficult.

In such a situation, the National Institute of Mental Health Measurement and Treatment Research to Improve Cognition in Schizophrenia (MATRICS) Initiative developed a consensus cognitive battery for schizophrenia research, that is the MATRICS Consensus Cognitive Battery (MCCB) ${ }^{40}$ The MCCB has been recommended as the standard battery for clinical trials of cognition enhancing interventions for schizophrenia by the US Food and Drug Administration. It is a comprehensive cognitive battery that contains not only neurocognitive domains but also social cognitive domains. On the other hand, as for functional outcome, there are no standardized scales at present. However, the six scales selected by the Validation of Everyday Real-World Outcomes (VALERO) study are often used..$^{41}$ The six scales are as follows: the Quality of Life Scale (QLS), the Specific Level of Functioning, the Social Behavior Schedule, the Social Functioning Scale (SFS), the Independent Living Skills Schedule, and the Life Skills Profile. Among these six scales, considering that the QLS was selected as one of the hybrid scales of social function and everyday living skills in the VALERO study, ${ }^{41}$ it is thought to be a comprehensive scale for evaluating social function.
Regarding research in this area, interest has shifted from whether cognitive function is related to functional outcome to how cognitive function is related to it. Not all types of cognitive function are equally important when it comes to navigating the real world, ${ }^{23}$ and as far as we know, it seems unclear which cognitive domain is related to which aspect of functional outcome. Using the Brief Assessment of Cognition in Schizophrenia (BACS) as a test battery of neurocognition, our research group has reported that speed of processing was correlated with the QLS total and all subscales scores and this cognitive domain was an independent predictor of the QLS total score. ${ }^{15}$ Moreover, since the MCCB was developed, several studies have also reported the relationship between cognitive function measured by it and functional outcome. ${ }^{42-52}$ However, among those studies, few evaluated social function using the QLS. ${ }^{46,49}$

Therefore, the purpose of the present study was to clarify the relationship between cognitive function measured comprehensively by the MCCB and social function measured by the QLS in people with schizophrenia. It was hypothesized that cognitive function, particularly social cognition, would be related to social function.

\section{Methods \\ Participants}

Fifty-five stabilized outpatients with a Diagnostic and Statistical Manual of Mental Disorders-IV diagnosis of schizophrenia were recruited from the Department of Psychiatry, Tokushima University Hospital. Patients with any organic central nervous system disorders, substance-related disorders, mental retardation, or severe somatic disorders were excluded. After receiving explanations on the content and possible disadvantages of the study as well as confidentiality protection, participants gave written informed consent to participate in this study. All of them had been receiving regular outpatient treatment and had not been hospitalized in the previous 6 months due to exacerbation of psychiatric symptoms.

The study was approved by the Ethics Committee of the University of Tokushima.

\section{Instruments}

To assess social function, we used the QLS. ${ }^{53}$ The QLS is a semi-structured interview that was specially constructed to measure quality of life (QOL) of schizophrenia patients. The reliability and validity of the scale have been confirmed..$^{53,54}$ The Japanese version had a good inter-rater reliability (intraclass correlation coefficients ranged from 0.75 to 0.98$){ }^{54}$ 
The ratings are based on patients' self-report and rater's judgment about the patient's functioning and life circumstances. This instrument consists of four subscales measured by a total of 21 items. The four subscales are interpersonal relations, instrumental role, intrapsychic foundations, and common objects and activities. Higher scores indicate a better level of social function. In the present study, experienced psychiatrists who had been treating patients and knew the patient's living circumstances carried out the interviews according to the Evaluation Manual for the QLS. ${ }^{54}$

To evaluate cognitive function, we used the MCCB which has been developed as a comprehensive measure of cognitive domains significantly impaired in schizophrenia. The MCCB consists of 10 tests that measure seven cognitive domains. They are as follows: speed of processing (Brief Assessment of Cognition in Schizophrenia-Symbol Coding [BACS-SC], Category Fluency Animal Naming [Fluency], and Trail Making Test Part A [TMT-A]), attention/vigilance (Continuous Performance Test-Identical Pairs), working memory (Wechsler Memory Scale III Spatial Span and Letter Number Span), verbal learning (Hopkins Verbal Learning Test-Revised), visual learning (Brief Visuospatial Memory Test-Revised), reasoning and problem solving (Neuropsychological Assessment Battery Maze), and social cognition (Mayer-Salovey-Caruso-Emotional Intelligence Test Managing Emotions [MSCEIT ME]). ${ }^{40}$ Each raw score for the 10 subtests was standardized to the $\mathrm{T}$-score ( mean $=50, \mathrm{SD}=10$ ). For the cognitive domain consisting of $>1$ test (speed of processing and working memory), the domain T-score was derived from a composite of the test scores within each domain. For cognitive domains other than the above, T-score represents the domain score. The MCCB composite score gives equal weighting to each of the seven cognitive domains. The MCCB has good testretest reliability, practicability, and tolerability, ${ }^{40}$ and it is reported that the Japanese version of the MCCB has good psychometric properties and validity. ${ }^{55}$ It was reported that the Japanese version had high internal consistency (Cronbach coefficient alpha was 0.72). ${ }^{55}$ In the present study, data were collected using the Japanese version by clinical psychologists who were well trained for the use of it. As for the data of the MCCB, only T-scores were used for statistical analysis. All participants were evaluated in a room for psychological tests, and it took about 1-2 hours to carry out the neurocognitive evaluation, during which, if needed, participants were able to take a break to avoid effects of fatigue on the examination. All concentrated on the tasks during the evaluation.
Clinical symptoms were evaluated using the Positive and Negative Syndrome Scale (PANSS) and the Calgary Depression Scale for Schizophrenia (CDSS). PANSS is used to assess the severity of various symptoms in people with schizophrenia. It was reported that the scale had a good reliability (the mean inter-rater correlations, Cronbach coefficient alpha, and test-retest reliability indexes for the PANSS scales ranged between 0.83 and $0.87,0.73$ and 0.83 , and 0.77 and 0.89 , respectively). ${ }^{56-58}$ It includes 30 items and higher scores represent a greater level of symptom severity. ${ }^{56}$ Experienced treating psychiatrists conducted the semi-structured interviews according to the Evaluation Manual for the PANSS. ${ }^{57}$ Depressive symptoms were evaluated using the CDSS which was specifically developed to distinguish depressive symptoms from non-depressed symptoms such as positive and negative symptoms or antipsychotic-induced adverse effects in schizophrenia. The scale consists of eight structured questions (depression, hopelessness, self-depreciation, guilty ideas of reference, pathological guilt, morning depression, early wakening, and suicide) followed by one observation item (observed depression) and higher scores represent a greater level of depression. ${ }^{59}$ The reliability and validity of the Japanese version of it have been confirmed. ${ }^{60}$ It was reported that the Japanese version of the scale had adequate internal consistency (Cronbach coefficient alpha was 0.82 ), inter-rater agreement (kappa coefficients ranged from 0.72 to 1.00), and test-retest reliability (test-retest reliability coefficient was 0.86). ${ }^{60}$ Experienced treating psychiatrists conducted the interviews according to the paper which included the manual for evaluation. ${ }^{61}$

Drug-induced extrapyramidal adverse effects were evaluated using the Drug-Induced Extrapyramidal Symptoms Scale (DIEPSS). The scale consists of eight individual parameters (gait, bradykinesia, sialorrhea, muscle rigidity, tremor, akathisia, dystonia, and dyskinesia) and one global assessment. Higher scores represent a greater level of extrapyramidal adverse effects. The scale has adequate interrater reliability (intra-class correlation coefficients ranged from 0.89 to 0.99 for a pair of experienced psychiatrists). ${ }^{62}$ In the present study, we evaluated the extrapyramidal symptoms score by summing eight individual parameters. Experienced psychiatrists who were treating the participants examined them according to the Rater's Manual for the DIEPSS. ${ }^{62}$

\section{Statistical analysis}

In order to identify significant associations between the QLS scores and other clinical variables including the MCCB scores, Pearson correlation coefficients were calculated. 
In addition, we used the false discovery rate correction to adjust for multiple testing. Then, the QLS total score and the subscale scores were chosen as dependent variables. Using the clinical variables that showed significant correlations with each dependent variable, stepwise regression analyses were performed to specify which clinical variables were the best predictor of each dependent variable. Statistical analyses were carried out with IBM SPSS Statistics version 22 for Windows (IBM Corporation, Armonk, NY, USA) and RStudio (RStudio, Inc, Boston, MA, USA; http://www. rstudio.com/).

\section{Results}

Table 1 presents the demographic characteristics and clinical variables of the participants. All participants were Japanese, of whom 28 were men and 27 women. Their mean age was 39.36 years $(\mathrm{SD}=10.65)$. All antipsychotic doses were converted to chlorpromazine equivalents using the conversion chart. $^{63}$

Table 2 shows the results of the correlation analyses between the QLS scores and the MCCB cognitive domain scores. Neither the MCCB cognitive domain score nor composite score was significantly correlated with the QLS scores. Table 3 shows the results of the correlation analyses between the QLS scores and the MCCB subtest scores. TMT-A was significantly correlated with the QLS total score $(r=0.39$, $p<0.05)$, interpersonal relations score $(r=0.37, p<0.05)$, intrapsychic foundations score $(r=0.39, p<0.05)$, and common object and activities score $(r=0.37, p<0.05)$. BACS-SC had significant correlations with the QLS total score $(r=0.37$, $p<0.05)$ and common objects and activities score $(r=0.42$, $p<0.05)$.

The results of the correlation analyses between the QLS scores and the clinical variables other than the MCCB scores are shown in Table 4. The PANSS positive syndrome scale score was significantly correlated with the QLS total score $(r=-0.45, p<0.01)$, interpersonal relations score $(r=-0.38, p<0.05)$, intrapsychic foundations score $(r=-0.48$, $p<0.01)$, and common objects and activities score $(r=-0.41$, $p<0.01)$. The PANSS negative syndrome scale score had significant correlations with the QLS total score $(r=-0.57$, $p<0.01)$, interpersonal relations score $(r=-0.49, p<0.01)$, instrumental role score $(r=-0.34, p<0.05)$, intrapsychic foundations score $(r=-0.63, p<0.01)$, and common objects and activities score $(r=-0.50, p<0.01)$. The CDSS score was significantly correlated with the QLS instrumental role score $(r=-0.41, p<0.01)$. The DIEPSS score showed significant correlations with the QLS total score $(r=-0.34, p<0.05)$,
Table I Demographic characteristics of participants

\begin{tabular}{|c|c|}
\hline $\mathrm{n}$ (men/women) & $55(28 / 27)$ \\
\hline Age (years) & $39.36 \pm 10.65$ \\
\hline Duration of illness (years) & $15.32 \pm 9.15$ \\
\hline Number of hospitalizations & $1.55 \pm 1.49$ \\
\hline Dose of antipsychotics (mg/day)* & $519.22 \pm 395.25$ \\
\hline \multicolumn{2}{|l|}{ Type of schizophrenia $(n)$} \\
\hline Paranoid & 40 \\
\hline Residual & 9 \\
\hline Disorganized & 5 \\
\hline Catatonic & 0 \\
\hline Undifferentiated & I \\
\hline \multicolumn{2}{|l|}{ Marital state $(n)$} \\
\hline Married & 8 \\
\hline Never married & 44 \\
\hline Divorced & 2 \\
\hline Widowed & I \\
\hline \multicolumn{2}{|l|}{ Social state $(n)$} \\
\hline Full time & 11 \\
\hline Part time & 27 \\
\hline No employment & 17 \\
\hline \multicolumn{2}{|l|}{ PANSS } \\
\hline Total & $76.40 \pm|4.6|$ \\
\hline Positive syndrome & $17.12 \pm 4.55$ \\
\hline Negative syndrome & $20.55 \pm 5.38$ \\
\hline CDSS (total) & $3.42 \pm 2.97$ \\
\hline DIEPSS (total) & $1.07 \pm 1.05$ \\
\hline \multicolumn{2}{|l|}{ MCCB (T-score) } \\
\hline Speed of processing & $18.00 \pm 24.60$ \\
\hline BACS-SC & $25.76 \pm 20.86$ \\
\hline Fluency & $41.82 \pm 11.48$ \\
\hline TMT-A & $31.44 \pm \mid 6.21$ \\
\hline Attention/vigilance (CPT-IP) & $36.60 \pm 10.29$ \\
\hline Working memory & $36.31 \pm 13.95$ \\
\hline WMS-III SS & $37.89 \pm 13.15$ \\
\hline LNS & $40.02 \pm 12.35$ \\
\hline Verbal learning (HVLT-R) & $39.53 \pm 13.00$ \\
\hline Visual learning (BVMT-R) & $42.49 \pm 10.31$ \\
\hline Reasoning and problem solving (NAB Maze) & $38.29 \pm 9.88$ \\
\hline Social cognition (MSCEIT ME) & $26.29 \pm 7.67$ \\
\hline Composite score & $|9.05 \pm| 8.3 \mid$ \\
\hline \multicolumn{2}{|l|}{ QLS } \\
\hline Total & $60.63 \pm 20.86$ \\
\hline Interpersonal relations & $20.27 \pm 8.6 \mathrm{I}$ \\
\hline Instrumental role & II. $34 \pm 5.84$ \\
\hline Intrapsychic foundations & $21.84 \pm 7.28$ \\
\hline Common objects and activities & $7.18 \pm 2.39$ \\
\hline
\end{tabular}

Notes: Data are expressed as mean \pm SD unless otherwise specified. *Chlorpromazine equivalent.

Abbreviations: PANSS, Positive and Negative Syndrome Scale; MCCB, Measurement and Treatment Research to Improve Cognition in Schizophrenia Consensus Cognitive Battery; BACS-SC, Brief Assessment of Cognition in Schizophrenia-Symbol Coding; Fluency, Category Fluency Animal Naming; TMT-A, Trail Making Test Part A; CPT-IP, Continuous Performance Test-Identical Pairs; WMS-III SS, Wechsler Memory Scale III Spatial Span; LNS, Letter Number Span; HVLT-R, Hopkins Verbal Learning Test-Revised; BVMT-R, Brief Visuospatial Memory Test-Revised; NAB, Neuropsychological Assessment Battery; MSCEIT ME, Mayer-Salovey-Caruso-Emotional Intelligence Test Managing Emotions; QLS, Quality of Life Scale; CDSS, Calgary Depression Scale for Schizophrenia; DIEPSS, Drug-Induced Extrapyramidal Symptoms Scale. 
Table 2 Correlation between QLS scores and MCCB cognitive domain scores

\begin{tabular}{llllll}
\hline & QLS & & & \\
\cline { 2 - 6 } & Total & $\begin{array}{l}\text { Interpersonal } \\
\text { relations }\end{array}$ & $\begin{array}{l}\text { Instrumental } \\
\text { role }\end{array}$ & $\begin{array}{l}\text { Intrapsychic } \\
\text { foundations }\end{array}$ & $\begin{array}{l}\text { Common objects } \\
\text { and activities }\end{array}$ \\
\hline Speed of processing & 0.30 & 0.29 & 0.14 & 0.30 & 0.35 \\
Attention/vigilance & 0.17 & 0.14 & 0.06 & 0.21 & 0.24 \\
Working memory & 0.18 & 0.13 & 0.12 & 0.17 & 0.25 \\
Verbal learning & 0.08 & 0.02 & -0.02 & 0.15 & 0.18 \\
Visual learning & 0.11 & 0.07 & 0.07 & 0.11 & 0.25 \\
Reasoning and problem solving & -0.04 & 0.05 & -0.18 & -0.03 & 0.03 \\
Social cognition & 0.28 & 0.30 & 0.11 & 0.31 & 0.16 \\
Composite score & 0.24 & 0.21 & 0.08 & 0.26 & 0.32 \\
\hline
\end{tabular}

Note: Pearson correlations (false discovery rate correction).

Abbreviations: MCCB, Measurement and Treatment Research to Improve Cognition in Schizophrenia Consensus Cognitive Battery; QLS, Quality of Life Scale.

interpersonal relations score $(r=-0.35, p<0.05)$, and common objects and activities score $(r=-0.36, p<0.05)$. However, no significant correlation was found between the QLS scores and duration of illness, number of hospitalizations, and dose of antipsychotics.

Table 5 shows the results of the stepwise regression analyses on the QLS scores. The PANSS negative syndrome scale score significantly predicted the QLS total and all subscale scores, and the CDSS score significantly predicted the instrumental role score. Concerning cognitive function, it was revealed that only BACS-SC was a significant predictor of the common objects and activities score but it had much less impact on the subscale than the PANSS negative syndrome scale score.

\section{Discussion}

Results of the correlation analysis in the present study show that TMT-A and BACS-SC to measure speed of processing in the MCCB are related to social function but negative symptoms are more important factors associated with various aspects of social function in people with schizophrenia. Concerning cognitive function, previous studies have shown the importance of speed of processing in functional outcome. ${ }^{15,46,47,64}$ Lin et al reported that all cognitive domains of the MCCB were significantly correlated with the QLS score and among the cognitive domains, speed of processing was most strongly correlated with the QLS score. ${ }^{46}$ Lystad et al found that the MCCB speed of processing, along with attention, was most strongly related to and predictive of occupational functioning evaluated by the Work Behavior Inventory. ${ }^{47}$ Using the BACS, our research group has already reported that speed of processing assessed with BACS-SC was significantly correlated with the QLS total and all subscales scores and it was an independent predictor of the QLS total score and intrapsychic foundations score. ${ }^{15}$ In the present study, the correlations between BACS-SC

Table 3 Correlation between QLS and MCCB subtests scores

\begin{tabular}{llllll}
\hline & QLS & & & \\
\cline { 2 - 6 } & Total & $\begin{array}{l}\text { Interpersonal } \\
\text { relations }\end{array}$ & $\begin{array}{l}\text { Instrumental } \\
\text { role }\end{array}$ & $\begin{array}{l}\text { Intrapsychic } \\
\text { foundations }\end{array}$ & $\begin{array}{l}\text { Common objects } \\
\text { and activities }\end{array}$ \\
\hline TMT-A & $0.39^{*}$ & $0.37^{*}$ & 0.22 & $0.39^{*}$ & $0.37^{*}$ \\
BACS-SC & $0.37^{*}$ & 0.34 & 0.22 & 0.35 & $0.42^{*}$ \\
HVLT-R & 0.08 & 0.02 & -0.02 & 0.15 & 0.18 \\
WMS-III SS & 0.10 & 0.10 & 0.02 & 0.11 & 0.16 \\
LNS & 0.21 & 0.14 & 0.19 & 0.20 & 0.28 \\
NAB Maze & -0.04 & 0.05 & -0.18 & -0.03 & 0.03 \\
BVMT-R & 0.11 & 0.07 & 0.07 & 0.11 & 0.25 \\
Fluency & -0.19 & -0.14 & -0.22 & -0.18 & -0.08 \\
MSCEIT ME & 0.28 & 0.30 & 0.11 & 0.31 & 0.16 \\
CPT-IP & 0.17 & 0.14 & 0.05 & 0.21 & 0.24 \\
\hline
\end{tabular}

Notes: Pearson correlations (false discovery rate correction). ${ }^{*} p<0.05$.

Abbreviations: MCCB, Measurement and Treatment Research to Improve Cognition in Schizophrenia Consensus Cognitive Battery; QLS, Quality of Life Scale; TMT-A, Trail Making Test Part A; BACS-SC, Brief Assessment of Cognition in Schizophrenia-Symbol Coding; HVLT-R, Hopkins Verbal Learning Test-Revised; WMS-III SS, Wechsler Memory Scale III Spatial Span; LNS, Letter Number Span; NAB, Neuropsychological Assessment Battery; BVMT-R, Brief Visuospatial Memory Test-Revised; Fluency, Category Fluency Animal Naming; MSCEIT ME, Mayer-Salovey-Caruso-Emotional Intelligence Test Managing Emotions; CPT-IP, Continuous Performance Test-Identical Pairs. 
Table 4 Correlation between QLS scores and other clinical variables

\begin{tabular}{|c|c|c|c|c|c|}
\hline & \multicolumn{5}{|l|}{ QLS } \\
\hline & Total & $\begin{array}{l}\text { Interpersonal } \\
\text { relations }\end{array}$ & $\begin{array}{l}\text { Instrumental } \\
\text { role }\end{array}$ & $\begin{array}{l}\text { Intrapsychic } \\
\text { foundations }\end{array}$ & $\begin{array}{l}\text { Common objects } \\
\text { and activities }\end{array}$ \\
\hline Duration of illness & -0.12 & -0.15 & -0.01 & -0.14 & -0.04 \\
\hline Number of hospitalizations & 0.10 & 0.10 & 0.13 & 0.05 & 0.03 \\
\hline Dose of antipsychotics & -0.18 & -0.14 & -0.07 & -0.22 & -0.28 \\
\hline \multicolumn{6}{|l|}{ PANSS } \\
\hline Positive syndrome & $-0.45^{* *}$ & $-0.38^{*}$ & -0.26 & $-0.48^{* *}$ & $-0.4 \mid * *$ \\
\hline Negative syndrome & $-0.57^{* *}$ & $-0.49 * *$ & $-0.34^{*}$ & $-0.63 * *$ & $-0.50 * *$ \\
\hline CDSS & -0.28 & -0.19 & $-0.4 I^{* *}$ & -0.20 & -0.13 \\
\hline DIEPSS & $-0.34 *$ & $-0.35 *$ & -0.23 & -0.27 & $-0.36 *$ \\
\hline
\end{tabular}

Notes: Pearson correlations (false discovery rate correction). ${ }^{*} p<0.05 ; * * p<0.01$.

Abbreviations: QLS, Quality of Life Scale; PANSS, Positive and Negative Syndrome Scale; CDSS, Calgary Depression Scale for Schizophrenia; DIEPSS, Drug-Induced Extrapyramidal Symptoms Scale.

and the QLS scores were weaker than those in our previous study. However, as a whole, the results of both the studies are similar. On the other hand, Savilla et al reported that BACS-SC was not correlated with the QLS total score and any of the QLS subscale scores. ${ }^{13}$ Fiszdon et al found a poor relationship between the digit-symbol subtest of WAIS-III and QLS scores. ${ }^{65}$ Ojeda et al showed that speed of processing assessed by TMT-A as well as by Stroop Color Test and digit-symbol coding of the WAIS-III was by far the most important cognitive factor that predicted QOL evaluated by the QLS. ${ }^{64}$ Our finding about TMT-A supports their result. Thus, some studies showed the relationship between speed of processing and functional outcome, but others did not. Although the relationship between the two seemed still unclear, the result of the present study clearly showed a significant relationship between them.

Speed of processing is thought to be a core domain in cognitive dysfunction in people with schizophrenia. ${ }^{27,66,67}$ Burton et al showed that a three-factor MCCB model representing speed of processing, attention/working memory, and learning fits the data well, and symbol coding that best predicted speed of processing proved to be the best single predictor of overall cognitive performance. ${ }^{66}$ However, fluency, one of the three tests that measure speed of processing in the MCCB, was not significantly correlated with the QLS scores in the present study. Fluency seems to include speed of speech, whereas TMT-A and BACS-SC seem to include speed of drawing or writing. Therefore, even though these three tests evaluate speed of processing, the cognitive processes they measure may be different. Actually, in the BACS, verbal fluency is regarded as an independent cognitive domain separate from attention and speed of information processing evaluated by BACS-SC. So, we guess that this might have led to no significant correlation between the speed of processing domain of the MCCB and the QLS scores in the present study.

There are some inconsistencies between the present study and previous studies about the relationship between cognitive function and functional outcome. In the present study, neither the neurocognitive domains other than speed of processing evaluated by TMT and BACS-SC, nor social cognition evaluated by MSCEIT ME was correlated significantly with functional outcome. These inconsistencies may

Table 5 Results of stepwise regression analyses on QLS

\begin{tabular}{llll}
\hline Dependent variable & Independent variable & Adjusted $\mathbf{R}^{2}$ & $\mathbf{B}$ \\
\hline Total & PANSS negative syndrome & $0.32^{* * *}$ & $-0.57^{* * *}$ \\
Interpersonal relations & PANSS negative syndrome & $0.22^{* * *}$ & $-0.49 * * *$ \\
Instrumental role & CDSS & $0.22^{* * *}$ & $-0.36^{* *}$ \\
& PANSS negative syndrome & $-0.28^{*}$ & $-0.52^{* * *}$ \\
Intrapsychic foundations & PANSS negative syndrome & $0.42^{* * *}$ & $-0.24^{*}$ \\
& PANSS positive syndrome & & $-0.4 I^{* *}$ \\
Common objects and activities & PANSS negative syndrome & $0.30^{* * *}$ & $0.29 *$ \\
\hline
\end{tabular}

Notes: $*_{p}<0.05 ; * * p<0.01$, $* * * p<0.001$.

Abbreviations: QLS, Quality of Life Scale; PANSS, Positive and Negative Syndrome Scale; CDSS, Calgary Depression Scale for Schizophrenia; BACS-SC, Brief Assessment of Cognition in Schizophrenia-Symbol Coding. 
be due to the differences of study design, sample population, sample size, and rating scales including cognitive tests. In fact, some studies reported no correlation between neurocognition and functional outcome. ${ }^{36,38}$ Concerning neurocognition, some researchers showed that verbal memory, working memory, executive function, and vigilance were significantly associated with functional outcome. ${ }^{31-33}$ More recently, a meta-analysis study revealed that a variety of neurocognitive domains such as reasoning and problem solving, processing speed, attention and vigilance, working memory, verbal learning and memory, visual learning and memory, verbal fluency, and overall neurocognition are significantly associated with functional outcome. ${ }^{39}$ Lystad et al reported that among the MCCB cognitive domains, working memory was the most highly correlated with months of previous employment and social function evaluated by the SFS and was a significant predictor of social function. ${ }^{48}$ Torgalsbøen et al showed that MCCB attention/vigilance was a significant predictor of social and role functioning assessed by Global Functioning. ${ }^{52}$ Concerning social cognition, the meta-analysis study described above showed that social cognition, particularly theory of mind was more strongly associated with functional outcome than neurocognition. ${ }^{39}$ In addition, Schmidt et al reported that social cognition mediated a significant indirect relationship between neurocognition and functional outcome. ${ }^{68}$ Social cognition consists of multiple domains as well as neurocognition. In schizophrenia, social cognition includes four core domains: "emotion processing" including emotion perception/recognition, understanding emotions, and managing emotions, "social perception" including social context processing and social knowledge, "theory of mind/mental state attribution," and "attributional style/bias." ${ }^{69}$ Nonetheless, many studies investigating the relationship between social cognition and functional outcome evaluated social cognition with emotion perception and/or social perception and/or theory of mind..$^{70-76}$ The MCCB chose MSCEIT ME as a test for social cognition because it is related to functional outcome. ${ }^{40}$ MSCEIT ME is a test to assess managing emotions. As there have been few studies investigating the relation between managing emotions and functional outcome, ${ }^{46,77-80}$ our result would add a new finding to this area of research.

As for the clinical variables other than cognitive function, the results of the present study indicate that positive and negative symptoms, extrapyramidal symptoms, and depressive symptoms are factors related to poor social function and, in particular, negative symptoms are key factors related to a wide range of social function. The present study shows almost the same findings as our previous studies. ${ }^{14-16,20}$ Other previous studies also have shown that these clinical variables are associated with functional outcome. ${ }^{10-13,17-19,21,22}$ Although neurocognition was reported to be a stronger predictor of functional outcome than symptomatology in some previous studies, ${ }^{33-35}$ in the present study, stepwise regression analysis clearly showed that negative symptoms predicted more strongly social function evaluated by the QLS than cognitive function. Several previous studies also have reported the superiority of psychiatric symptoms over cognitive function in relation to functional outcome. ${ }^{36-38}$ In the present study, we evaluated clinical symptoms and functional outcome using the PANSS and QLS, respectively. Conceptual overlap between the items of PANSS and QLS may explain the strong relationship between the two scales to some extent. Particularly, the items of the PANSS negative syndrome scale and the QLS intrapsychic foundations subscale seem to be rather similar. Apart from those findings, it was revealed that the CDSS score predicted the QLS instrumental role subscale score more strongly than the PANSS negative syndrome scale. This finding is consistent with our previous study. ${ }^{15}$ As the role of a worker, student, or housekeeper/ parent evaluated by the QLS instrumental role subscale is thought to be one of the highest social functions, many factors other than cognitive function could affect this domain. This may partly explain the absence of a significant relation between cognitive function and the QLS instrumental role subscale score in the present study. Although the finding that negative symptoms are related to social function has already been reported in previous studies, ${ }^{12-20}$ we have found that the cognitive function of processing speed evaluated by TMT-A and BACS-SC is related to social function and BACS-SC predicts a certain part of social function.

The present study has some limitations. First, because of the cross-sectional study, the causal relationship between clinical variables and social function could not be determined. Second, the sample size was small. Therefore, further research with a larger sample size may be required to confirm the results. Third, as the sample was composed exclusively of stabilized outpatients, the results cannot be generalized to all schizophrenia patients. Fourth, although motivation, ${ }^{81}$ incentives, ${ }^{82,83}$ or stigma ${ }^{84}$ could affect social function, these factors were not examined in the present study.

\section{Conclusion}

As a whole, the results of the present study did not support our hypothesis. They indicate that speed of processing evaluated by BACS-SC in the MCCB could predict some 
aspect of social function but negative symptoms have a much greater impact on global social function in people with schizophrenia.

\section{Acknowledgment}

We are grateful to Ms Mai Doi, Ms Atsuko Watanabe, Ms Ayako Kamitani, and Ms Ayano Arai for their help with cognitive assessment.

\section{Disclosure}

The authors report no conflicts of interest in this work.

\section{References}

1. Leonhardt BL, Huling K, Hamm JA, et al. Recovery and serious mental illness: a review of current clinical and research paradigms and future directions. Expert Rev Neurother. 2017;17(11):1117-1130.

2. Bellack AS, Morrison RL, Wixted JT, Mueser KT. An analysis of social competence in schizophrenia. Br J Psychiatry. 1990;156:809-818.

3. Gupta S, Andreasen NC, Arndt S, Flaum M, Hubbard WC, Ziebell S. The Iowa Longitudinal Study of Recent Onset Psychosis: one-year follow-up of first episode patients. Schizophr Res. 1997;23(1):1-13.

4. Hegarty JD, Baldessarini RJ, Tohen M, Waternaux C, Oepen G. One hundred years of schizophrenia: a meta-analysis of the outcome literature. Am J Psychiatry. 1994;151(10):1409-1416.

5. Robinson DG, Woerner MG, McMeniman M, Mendelowitz A, Bilder RM. Symptomatic and functional recovery from a first episode of schizophrenia or schizoaffective disorder. Am J Psychiatry. 2004; 161(3):473-479.

6. Wiersma D, Wanderling J, Dragomirecka E, et al. Social disability in schizophrenia: its development and prediction over 15 years in incidence cohorts in six European centres. Psychol Med. 2000;30(5): 1155-1167.

7. Harvey PD, Bellack AS. Toward a terminology for functional recovery in schizophrenia: is functional remission a viable concept? Schizophr Bull. 2009;35(2):300-306.

8. Sumiyoshi T, Sumiyoshi C. Functional outcome in patients with schizophrenia: the concept and the measurement. Act Nerv Super. 2015; 57(1):1-11.

9. Burns T, Patrick D. Social functioning as an outcome measure in schizophrenia studies. Acta Psychiatr Scand. 2007;116(6):403-418.

10. Eack SM, Newhill CE. Psychiatric symptoms and quality of life in schizophrenia: a meta-analysis. Schizophr Bull. 2007;33(5):1225-1237.

11. Hofer A, Rettenbacher MA, Widschwendter CG, Kemmler G, Hummer M, Fleischhacker WW. Correlates of subjective and functional outcomes in outpatient clinic attendees with schizophrenia and schizoaffective disorder. Eur Arch Psychiatry Clin Neurosci. 2006;256(4): 246-255.

12. Rabinowitz J, Levine SZ, Garibaldi G, Bugarski-Kirola D, Berardo CG, Kapur S. Negative symptoms have greater impact on functioning than positive symptoms in schizophrenia: analysis of CATIE data. Schizophr Res. 2012;137(1-3):147-150.

13. Savilla K, Kettler L, Galletly C. Relationships between cognitive deficits, symptoms and quality of life in schizophrenia. Aust $N Z J$ Psychiatry. 2008;42(6):496-504.

14. Tomotake M, Kaneda Y, Iga J, et al. Subjective and objective measures of quality of life have different predictors for people with schizophrenia. Psychol Rep. 2006;99(2):477-487.

15. Ueoka Y, Tomotake M, Tanaka T, et al. Quality of life and cognitive dysfunction in people with schizophrenia. Prog Neuropsychopharmacol Biol Psychiatry. 2011;35(1):53-59.
16. Aki H, Tomotake M, Kaneda Y, et al. Subjective and objective quality of life, levels of life skills, and their clinical determinants in outpatients with schizophrenia. Psychiatry Res. 2008;158(1):19-25.

17. Browne S, Roe M, Lane A, et al. Quality of life in schizophrenia: relationship to sociodemographic factors, symptomatology and tardive dyskinesia. Acta Psychiatr Scand. 1996;94(2):118-124.

18. Fervaha G, Foussias G, Agid O, Remington G. Impact of primary negative symptoms on functional outcomes in schizophrenia. Eur Psychiatry. 2014;29(7):449-455.

19. Strejilevich SA, Palatnik A, Avila R, et al. Lack of extrapyramidal side effects predicts quality of life in outpatients treated with clozapine or with typical antipsychotics. Psychiatry Res. 2005;133(2-3):277-280.

20. Yamauchi K, Aki H, Tomotake M, et al. Predictors of subjective and objective quality of life in outpatients with schizophrenia. Psychiatry Clin Neurosci. 2008;62(4):404-411.

21. Jin H, Zisook S, Palmer BW, Patterson TL, Heaton RK, Jeste DV. Association of depressive symptoms with worse functioning in schizophrenia: a study in older outpatients. J Clin Psychiatry. 2001;62(10): 797-803.

22. Rocca P, Bellino S, Calvarese P, et al. Depressive and negative symptoms in schizophrenia: different effects on clinical features. Compr Psychiatry. 2005;46(4):304-310.

23. Green MF, Harvey PD. Cognition in schizophrenia: past, present, and future. Schizophr Res Cogn. 2014;1(1):e1-e9.

24. Kraus MS, Keefe RS. Cognition as an outcome measure in schizophrenia. Br J Psychiatry Suppl. 2007;50:s46-s51.

25. Kahn RS, Keefe RS. Schizophrenia is a cognitive illness: time for a change in focus. JAMA Psychiatry. 2013;70(10):1107-1112.

26. Palmer BW, Dawes SE, Heaton RK. What do we know about neuropsychological aspects of schizophrenia? Neuropsychol Rev. 2009; 19(3):365-384.

27. Dickinson D, Ramsey ME, Gold JM. Overlooking the obvious: a meta-analytic comparison of digit symbol coding tasks and other cognitive measures in schizophrenia. Arch Gen Psychiatry. 2007;64(5): 532-542.

28. Reichenberg A. The assessment of neuropsychological functioning in schizophrenia. Dialogues Clin Neurosci. 2010;12(3):383-392.

29. Reichenberg A, Harvey PD. Neuropsychological impairments in schizophrenia: integration of performance-based and brain imaging findings. Psychol Bull. 2007;133(5):833-858.

30. Harvey PD, Penn D. Social cognition: the key factor predicting social outcome in people with schizophrenia? Psychiatry (Edgmont). 2010; $7(2): 41-44$.

31. Green MF. What are the functional consequences of neurocognitive deficits in schizophrenia? Am J Psychiatry. 1996;153(3):321-330.

32. Green MF, Kern RS, Heaton RK. Longitudinal studies of cognition and functional outcome in schizophrenia: implications for MATRICS. Schizophr Res. 2004;72(1):41-51.

33. Green MF, Kern RS, Braff DL, Mintz J. Neurocognitive deficits and functional outcome in schizophrenia: are we measuring the "right stuff"? Schizophr Bull. 2000;26(1):119-136.

34. Christensen TØ. The influence of neurocognitive dysfunctions on work capacity in schizophrenia patients: a systematic review of the literature. Int J Psychiatry Clin Pract. 2007;11(2):89-101.

35. Velligan DI, Mahurin RK, Diamond PL, Hazleton BC, Eckert SL, Miller AL. The functional significance of symptomatology and cognitive function in schizophrenia. Schizophr Res. 1997;25(1):21-31.

36. Ertuğrul A, Uluğ $\mathrm{B}$. The influence of neurocognitive deficits and symptoms on disability in schizophrenia. Acta Psychiatr Scand. 2002; 105(3):196-201.

37. Mohamed S, Rosenheck R, Swartz M, Stroup S, Lieberman JA, Keefe RS. Relationship of cognition and psychopathology to functional impairment in schizophrenia. Am J Psychiatry. 2008;165(8):978-987.

38. Norman RM, Malla AK, Cortese L, et al. Symptoms and cognition as predictors of community functioning: a prospective analysis. $\mathrm{Am} \mathrm{J}$ Psychiatry. 1999;156(3):400-405. 
39. Fett AK, Viechtbauer W, Dominguez MD, Penn DL, van Os J, Krabbendam L. The relationship between neurocognition and social cognition with functional outcomes in schizophrenia: a meta-analysis. Neurosci Biobehav Rev. 2011;35(3):573-588.

40. Nuechterlein KH, Green MF, Kern RS, et al. The MATRICS Consensus Cognitive Battery, part 1: test selection, reliability, and validity. Am J Psychiatry. 2008;165(2):203-213.

41. Leifker FR, Patterson TL, Heaton RK, Harvey PD. Validating measures of real-world outcome: the results of the VALERO expert survey and RAND panel. Schizophr Bull. 2011;37(2):334-343.

42. August SM, Kiwanuka JN, McMahon RP, Gold JM. The MATRICS Consensus Cognitive Battery (MCCB): clinical and cognitive correlates. Schizophr Res. 2012;134(1):76-82.

43. Durand D, Strassnig M, Sabbag S, et al. Factors influencing self-assessment of cognition and functioning in schizophrenia: implications for treatment studies. Eur Neuropsychopharmacol. 2015;25(2):185-191.

44. Gould F, McGuire LS, Durand D, et al. Self-assessment in schizophrenia: accuracy of evaluation of cognition and everyday functioning Neuropsychology. 2015;29(5):675-682.

45. Kern RS, Gold JM, Dickinson D, et al. The MCCB impairment profile for schizophrenia outpatients: results from the MATRICS psychometric and standardization study. Schizophr Res. 2011;126(1-3):124-131.

46. Lin $\mathrm{CH}$, Huang $\mathrm{CL}$, Chang YC, et al. Clinical symptoms, mainly negative symptoms, mediate the influence of neurocognition and socia cognition on functional outcome of schizophrenia. Schizophr Res. 2013; 146(1-3):231-237.

47. Lystad JU, Falkum E, Haaland VØ, et al. Neurocognition and occupational functioning in schizophrenia spectrum disorders: the MATRICS Consensus Cognitive Battery (MCCB) and workplace assessments Schizophr Res. 2016;170(1):143-149.

48. Lystad JU, Falkum E, Mohn C, et al. The MATRICS Consensus Cognitive Battery (MCCB): performance and functional correlates. Psychiatry Res. 2014;220(3):1094-1101.

49. Sabbag S, Twamley EM, Vella L, Heaton RK, Patterson TL, Harvey PD. Assessing everyday functioning in schizophrenia: not all informants seem equally informative. Schizophr Res. 2011;131(1-3):250-255.

50. Shamsi S, Lau A, Lencz T, et al. Cognitive and symptomatic predictors of functional disability in schizophrenia. Schizophr Res. 2011; 126(1-3):257-264.

51. Sumiyoshi C, Harvey PD, Takaki M, et al. Factors predicting work outcome in Japanese patients with schizophrenia: role of multiple functioning levels. Schizophr Res Cogn. 2015;2(3):105-112.

52. Torgalsbøen AK, Mohn C, Czajkowski N, Rund BR. Relationship between neurocognition and functional recovery in first-episode schizophrenia: results from the second year of the Oslo multi-follow-up study. Psychiatry Res. 2015;227(2-3):185-191.

53. Heinrichs DW, Hanlon TE, Carpenter WT Jr. The Quality of Life Scale: an instrument for rating the schizophrenic deficit syndrome. Schizophr Bull. 1984;10(3):388-398.

54. Heinrichs DW, Hanlon T, Carpenter WT Jr. The Quality of Life Scale. Tokyo: Seiwa Publishers; 2001. Japanese.

55. Kaneda Y, Ohmori T, Okahisa Y, et al. Measurement and Treatment Research to Improve Cognition in Schizophrenia Consensus Cognitive Battery: validation of the Japanese version. Psychiatry Clin Neurosci. 2013;67(3):182-188.

56. Kay SR, Fiszbein A, Opler LA. The positive and negative syndrome scale (PANSS) for schizophrenia. Schizophr Bull. 1987;13(2): 261-276.

57. Kay SR, Opler LA, Fiszbein A. Positive and Negative Syndrome Scale (PANSS) Rating Manual. Tokyo: Seiwa Publishers; 1991. Japanese.

58. Kay SR, Opler LA, Lindenmayer JP. Reliability and validity of the positive and negative syndrome scale for schizophrenics. Psychiatry Res. 1988;23(1):99-110.

59. Addington D, Addington J, Maticka-Tyndale E. Assessing depression in schizophrenia: the Calgary Depression Scale. Br J Psychiatry. 1993;163(Suppl 22):39-44.
60. Kaneda Y, Fujii A, Ohmori T. Psychometric properties of the Japanese version of the Calgary Depression Scale for Schizophrenics. J Nerv Ment Dis. 2000;188(4):237-239.

61. Kaneda Y, Ohmori T, Addington D. [The Calgary Depression Scale for Schizophrenia]. No To Shinkei. 2000;52(2):163-166. Japanese.

62. Inada T. Evaluation and Diagnosis of Drug-Induced Extrapyramidal Symptoms: Commentary on the DIEPSS and Guide to its Usage. Tokyo: Seiwa Publishers; 1996. Japanese.

63. Inada T, Inagaki A. Psychotropic dose equivalence in Japan. Psychiatry Clin Neurosci. 2015;69(8):440-447.

64. Ojeda N, Sánchez P, Peña J, et al. An explanatory model of quality of life in schizophrenia: the role of processing speed and negative symptoms. Actas Esp Psiquiatr. 2012;40(1):10-18.

65. Fiszdon JM, Choi J, Goulet J, Bell MD. Temporal relationship between change in cognition and change in functioning in schizophrenia. Schizophr Res. 2008;105(1-3):105-113.

66. Burton CZ, Vella L, Harvey PD, Patterson TL, Heaton RK, Twamley EW. Factor structure of the MATRICS Consensus Cognitive Battery (MCCB) in schizophrenia. Schizophr Res. 2013;146(1-3):244-248.

67. Rodríguez-Sánchez JM, Crespo-Facorro B, González-Blanch C, Perez-Iglesias R, Vázquez-Barquero JL. Cognitive dysfunction in firstepisode psychosis: the processing speed hypothesis. Br J Psychiatry. 2007;(Suppl 51):s107-s110.

68. Schmidt SJ, Mueller DR, Roder V. Social cognition as a mediator variable between neurocognition and functional outcome in schizophrenia: empirical review and new results by structural equation modeling. Schizophr Bull. 2011;37(Suppl 2):S41-S54.

69. Pinkham AE, Penn DL, Green MF, Buck B, Healey K, Harvey PD. The social cognition psychometric evaluation study: results of the expert survey and RAND panel. Schizophr Bull. 2014;40(4):813-823.

70. Brekke J, Kay DD, Lee KS, Green MF. Biosocial pathways to functional outcome in schizophrenia. Schizophr Res. 2005;80(2-3):213-225.

71. Bora E, Eryavuz A, Kayahan B, Sungu G, Veznedaroglu B. Social functioning, theory of mind and neurocognition in outpatients with schizophrenia; mental state decoding may be a better predictor of social functioning than mental state reasoning. Psychiatry Res. 2006; 145(2-3):95-103.

72. Meyer MB, Kurtz MM. Elementary neurocognitive function, facial affect recognition and social-skills in schizophrenia. Schizophr Res. 2009;110(1-3):173-179.

73. Pijnenborg GH, Withaar FK, Evans JJ, van den Bosch RJ, Timmerman ME, Brouwer WH. The predictive value of measures of social cognition for community functioning in schizophrenia: implications for neuropsychological assessment. J Int Neuropsychol Soc. 2009; 15(2):239-247.

74. Pinkham AE, Penn DL. Neurocognitive and social cognitive predictors of interpersonal skill in schizophrenia. Psychiatry Res. 2006; 143(2-3):167-178.

75. Sergi MJ, Rassovsky Y, Nuechterlein KH, Green MF. Social perception as mediator of the influence of early visual processing on functional status in schizophrenia. Am J Psychiatry. 2006;163(3):448-454.

76. Vaskinn A, Sundet K, Friis S, et al. Emotion perception and learning potential: mediators between neurocognition and social problemsolving in schizophrenia? J Int Neuropsychol Soc. 2008;14(2): 279-288.

77. Eack SM, Greeno CG, Pogue-Geile MF, Newhill CE, Hogarty GE, Keshavan MS. Assessing social-cognitive deficits in schizophrenia with the Mayer-Salovey-Caruso Emotional Intelligence Test. Schizophr Bull. 2010;36(2):370-380.

78. Eack SM, Pogue-Geile MF, Greenwald DP, Hogarty SS, Keshavan MS. Mechanisms of functional improvement in a 2-year trial of cognitive enhancement therapy for early schizophrenia. Psychol Med. 2011;41(6):1253-1261.

79. Fiszdon JM, Fanning JR, Johannesen JK, Bell MD. Social cognitive deficits in schizophrenia and their relationship to clinical and functional status. Psychiatry Res. 2013;205(1-2):25-29. 
80. Kee KS, Horan WP, Salovey P, et al. Emotional intelligence in schizophrenia. Schizophr Res. 2009;107(1):61-68.

81. Najas-Garcia A, Gómez-Benito J, Huedo-Medina TB. The relationship of motivation and neurocognition with functionality in schizophrenia: a meta-analytic review. Community Ment Health J. Epub 2018 Mar 31.

82. Reddy LF, Llerena K, Kern RS. Predictors of employment in schizophrenia: the importance of intrinsic and extrinsic motivation. Schizophr Res. 2016;176(2-3):462-466.
83. Silverstein SM. Bridging the gap between extrinsic and intrinsic motivation in the cognitive remediation of schizophrenia. Schizophr Bull. 2010;36(5):949-956.

84. Cavelti M, Rüsch N, Vauth R. Is living with psychosis demoralizing? Insight, self-stigma, and clinical outcome among people with schizophrenia across 1 year. J Nerv Ment Dis. 2014;202(7):521-529.

\section{Publish your work in this journal}

Neuropsychiatric Disease and Treatment is an international, peerreviewed journal of clinical therapeutics and pharmacology focusing on concise rapid reporting of clinical or pre-clinical studies on a range of neuropsychiatric and neurological disorders. This journal is indexed on PubMed Central, the 'PsycINFO' database and CAS, and is the official journal of The International Neuropsychiatric Association (INA). The manuscript management system is completely online and includes a very quick and fair peer-review system, which is all easy to use. Visit http://www.dovepress.com/testimonials.php to read real quotes from published authors.

Submit your manuscript here: http://www.dovepress.com/neuropsychiatric-disease-and-treatment-journal 